\title{
El uso terapéutico de células troncales humanas (la mal llamada "clonación terapéutica"). Realidad científico-técnica y discernimiento ético
}

PROF. DR. D. MARCIANO VIDAL

A mediados del mes de agosto del año de 2000, exactamente el 16 de agosto, el Gobierno del Reino Unido aceptó tramitar la aceptación legal de la mal llamada "clonación humana terapéutica", siguiendo la recomendación positiva de la comisión de expertos a los que había solicitado un informe sobre este tipo de experimentación médica (Informe de 150 pp. del equipo dirigido por el profesor Liam Donaldson).

Representantes oficiales de diversos países de la Unión Europea así como el Parlamento Europeo fueron críticos ante esta iniciativa del gobierno británico. La crítica del Vaticano también fue inmediata y dura. Sin embargo, siete días después, Estados Unidos se sumó a la iniciativa británica autorizando el uso de fondos públicos para financiar proyectos de investigación y manipulación de las células madre o troncales, procedentes de la destrucción de embriones fertilizados y no utilizados en fecundación in vitro.

La discusión estaba servida. A la posibilidad de la clonación humana propiamente tal (la llamada clonación "reproductiva") se sumaba ahora el posible y más cercano uso terapéutico de células troncales humanas: 
un procedimiento que se sirve de la técnica usada para clonar la oveja Dolly, pero que no conduce a la formación de un individuo clonado, sino que se detiene en la fase en que las células son pluripotenciales ( $o$, al menos multipotenciales); de éstas células se obtendrían líneas específicas de tejidos (y órganos) para, una vez sometidas a determinado cultivo, se implantarían en el propio organismo.

A este nuevo procedimiento no le cuadra con exactitud el término de clonación, sino el de terapia celular mediante el cultivo de células troncales y su ulterior implantación autológica o el de uso terapéutico de células troncales dentro de un mismo organismo. Más que de clonación se trata de la investigación y del posible uso terapéutico de células troncales humanas, sean éstas embrionarias o de otra procedencia. A veces, para referirse a esta realidad se utiliza la sigla TNSA: Transferencia Nuclear para la producción de células troncales (Stem Cells) Autológicas.

En las páginas que siguen me propongo analizar la dimensión ética de esta nueva posibilidad científico-técnica. Desarrollo la exposición en cuatro apartados, cada uno de los cuales constituye una perspectiva peculiar de las que componen el significado total del tema:

Perspectiva científica: datos científico-técnicos más relevantes.

Perspectiva social: posturas de la opinión pública y de la comunidad científica.

Perspectiva jurídica: decisiones legales y administrativas.

Perspectiva ética: discernimiento ético, dentro del cual incluyo la doctrina de la Iglesia católica y la reflexión teológica.

DATOS CIENTÍFICO-TÉCNICOS MÁS RELEVANTES

\section{LAS CÉLULAS TRONCALES}

La utilización de la terapia celular se basa en el autotrasplante de células o tejidos (u órganos) dentro de un organismo con el fin de subsa- 
nar deficiencias en determinadas células o tejidos ( $u$ órganos) de ese mismo organismo. Las células o tejidos ( $u$ órganos) para el trasplante han de proceder del cultivo a partir de células troncales o células madre, sean éstas embrionarias o somáticas ${ }^{3}$.

He aquí algunos datos científicos a tener en cuenta en orden a una ulterior valoración ética. "Por célula troncal se entiende cualquier célula que tiene la doble capacidad de dividirse ilimitadamente y de dar lugar a diferentes tipos de células especializadas. De acuerdo con esta segunda capacidad, las células troncales pueden ser totipotentes, pluripotentes y multipotentes en razón a su mayor o menor versatilidad o potencialidad, tal como se definen a continuación:

Célula totipotente: Célula troncal que tiene la capacidad de diferenciarse en el embrión y en tejidos y membranas extraembriónicas. Las células totipotentes contribuyen a todos los tipos celulares de un organismo adulto. La totipotencia es la capacidad funcional de una célula de dar lugar a un individuo completo tras un proceso de desarrollo normal. Las células totipotentes de un embrión muy temprano tienen la capacidad de diferenciarse en membranas y tejidos extraembriónicos, en el embrión y en todos los tejidos y órganos postembriónicos. En el embrión humano, parece ser que solamente son totipotentes los blastómeros hasta el estadio de mórula de 16 células.

Célula pluripotente: Célula troncal presente en los estadios tempranos de desarrollo embrionario que puede generar todos los tipos de células en el feto y en el adulto y es capaz de autorrenovación. Las células pluripotentes, sin embargo, no son capaces de desarrollarse en un organismo completo. La pluripotencia es la capacidad funcional de una célula de dar lugar a varios linajes celulares o tejidos diferentes. Las células troncales embrionarias (ES) presentes en la masa celular interna del blastocisto humano son pluripotentes, pero no totipotentes; es decir, pueden originar distintos tejidos u órganos pero no dar lugar al desarrollo completo de un embrión porque no pueden producir las membranas y tejidos extraembriónicos necesarios para el proceso de gesta- 
ción. No obstante, podría ocurrir que una célula pluripotente de la masa celular interna se convirtiera en totipotente.

Célula multipotente: Célula troncal presente en los tejidos u órganos adultos que tiene una capacidad limitada de reactivar su programa genético como respuesta a determinados estímulos que le permiten dar lugar a algunos, pero no todos, los linajes celulares diferenciados. La multipotencia es la capacidad funcional de una célula de dar lugar a alguno, pero no todos, los linajes celulares. Algunas células troncales presentes en tejidos $\mathrm{u}$ órganos adultos son multipotentes. A veces se utiliza el término plasticidad como equivalente a multipotencia"2.

Las células troncales se pueden clasificar, por razón de su origen, en: embrionarias, fetales, adultas. Las de origen embrionario se obtienen de la masa celular interna del blastocisto (embrión de 5-7 días); las de origen fetal, de tejidos cadavéricos fetales de más de ocho semanas; y las de adulto, de tejidos desarrollados vivos. "En algunos tejidos u órganos puede haber células capaces de reactivar su programa genético como respuesta a determinadas señales de estimulación y dar lugar a alguno, no todos, de los linajes celulares posibles. Es decir, se trataría de células multipotentes con un grado potencial de diferenciación inferior al de las células pluripotentes. Tal podría ser el caso de las células troncales neurales y de las células troncales del mesénquima"3.

\section{¿DE DÓNDE SE OBTIENEN LAS CÉLULAS TRONCALES HUMANAS?}

Es ésta una decisiva cuestión para la ética y para el derecho, ya que la valoración moral y la normativa legal dependen, en gran medida, de la condición de vida humana que posean las células troncales de las que se cultivan las líneas celulares en orden a producir tejidos (u órganos) para autotrasplantes. Esto vale, de modo especial, para las posturas éticas que descubren en el embrión humano un estatuto antropológico de dignidad plenamente humana, una dignidad que no poseen las células somáticas.

La procedencia primera de las células troncales es la de embriones humanos. Pero, como alternativa al uso de embriones, se han llegado a 
proponer alrededor de otros 20 procedimientos para obtener células troncales humanas. Señalo a continuación las fuentes principales, ordenándolas en tres grupos.

\section{CÉLULAS TRONCALES PROCEDENTES DE EMBRIONES HUMANOS}

Por razón de su procedencia, a estas células troncales se las denomina embrionales ( $\mathrm{ES}=$ embrionic stem cells). Son las que ofrecen mayores ventajas para la investigación y para su ulterior uso terapéutico, precisamente por el estadio de indiferenciación o de plasticidad en que se encuentran: poseen la cualidad de la "totipotencialidad" (en el estadio inicial de 2, 4, 8 células: blastómeros) o de la "pluripontencialidad (en el estadio de mórula: 16, 32, 64 células).

Las fuentes más importantes de las células troncales embrionales son:

Embriones producidos en las técnicas de reproducción humana asistida (fecundación in vitro): de los que restan después de la implantación se obtienen las células madre en orden al cultivo de líneas celulares para la investigación (y para el futuro uso terapéutico). Para eludir las trabas de las legislaciones que prohíben utilizar embriones para la clonación terapéutica, algunos proponen servirse de los embriones no viables ${ }^{4}$. De hecho, para algunos investigadores las quimeras embrionarias podrían proporcionar material celular sin problemas éticos especiales.

Los embriones sobrantes de las técnicas de reproducción humana asistida y que, según diversas legislaciones, han tenido que ser congelados. Muchos investigadores piden a las autoridades correspondientes que, pasado el plazo legal de permanencia para la reproducción asistida (un plazo medio de cinco años), puedan ser utilizados para la investigación de la clonación terapéutica. Hay legislaciones - como la alemanaque no permiten congelar embriones (no aceptan embriones sobrantes); pero la mayor parte de ellas - la española, la francesa, la inglesa, etc.ordenan congelar los embriones sobrantes. En esos países existe un nú- 
mero elevado de embriones sobrantes congelados. Hay quienes (como el doctor Marcelo Palacios, "padre" de la ley española sobre Técnicas de reproducción asistida) opinan que los embriones sobrantes que han pasado el período legal de crioconservación pueden ser considerados como embriones no viables.

Embriones producidos con la técnica de la clonación y destinados expresamente a la obtención de líneas celulares para su cultivo y para el subsiguiente uso terapéutico del autotrasplante celular (o de tejido, o de órgano).

En Estados Unidos (y en otros países: Japón, etc.) las empresas privadas son libres para producir embriones destinados a la investigación y al uso terapéutico. Según anotaré, alguna empresa ha anunciado ya su trabajo en esta dirección. Hay también legislaciones que permiten este tipo de actuaciones: Reino Unido, Canadá, Bélgica, etc. En el Reino Unido ya han presentado la solicitud correspondiente (a los Comités de Ética científica) varios equipos de investigación.

La Administración de Estados Unidos proporciona fondos económicos para investigar sobre células troncales embrionarias, pero no para producirlas; las células han de ser obtenidas sin ayuda de los fondos federales. Situación parecida se da en Alemania: se permite investigar con células troncales embrionarias obtenidas fuera del país.

Las expectativas de los investigadores de otros países de la UE (España, Francia, etc.) se sitúan, por el momento, en que sea permitido investigar con los embriones sobrantes de las técnicas de reproducción asistida.

En la legislación española sobre técnicas de reproducción asistida se permite investigar con los embriones no viables (no implantables). Algunos piensan que los embriones sobrantes congelados, una vez pasado el plazo legal de permanencia, pueden ser considerados dentro de la categoría legal de embriones no viables. Pero son muchos más los que creen que para que esa interpretación pueda ser llevada a la práctica se precisa una intervención en ese sentido de la Autoridad competente. 
Pensando en esa intervención administrativa, los científicos del Instituto Valenciano de Infertilidad han presentado al Ministerio de Sanidad un método para identificar los embriones no viables; se trata, en concreto, de identificar los embriones que, en un $5 \%$ de casos, se han producido mediante la fecundación de dos espermatozoides, cuyos dos núcleos pueden ser visualizados situando el embrión bajo un microscopio ${ }^{6}$.

CÉLULAS TRONCALES PROCEDENTES DE TEJIDOS U ÓRGANOS ADULTOS

Hay células somáticas con capacidad de reactivar su programa genético como respuesta a determinadas señales de estimulación y volver a la condición de células troncales (AS = adult stem cells). No todas las células somáticas son reprogramables. Por otra parte, esas células troncales no alcanzarían la cualidad ni de la "totipontencialidad" ni de la "pluripotencialidad". Serían células multipotentes.

La reprogramación de las células somáticas para reconvertirlas en células troncales es un hallazgo importante de la ciencia y de la técnica. La revista Science (17 de diciembre de 1999) consideró este resultado como uno de los hallazgos más importantes de la investigación científica del año 1999.

Obviamente, las células troncales embrionarias ofrecen mayores posibilidades para la investigación. Por otra parte, son más fáciles de obtener. De ahí que los investigadores acudan a ellas de forma preferente. Por otra parte, existe una discusión científica sobre la funcionalidad efectiva de las células troncales somáticas en orden a su uso terapéutico en determinados autotrasplantes de células (de tejidos o de órganos).

\section{OTRAS PROCEDENCIAS}

Las fuentes de obtención de células troncales no se agotan en el embrión y en los tejidos u órganos adultos. Aparecen en el horizonte otras posibilidades, como las siguientes:

Células troncales a partir de fetos abortados (abortos espontáneos); se trata de células germinales embrionarias ( $E G=$ embryonic germ cells). 
Células troncales obtenidas del cordón umbilical. Ya existe una tendencia a solicitar la "donación" y a constituir "bancos" de cordones umbilicales?.

Obtención de líneas de células troncales a partir de óvulos sin llegar a la fase de embrión. Este tipo de investigación ha sido apoyado por la Comisión Nacional de Bioética italiana y ha obtenido una aceptación positiva de parte del Vaticano.

Células troncales obtenidas directamente de tejidos del propio paciente (músculos, médula ósea, sistema nervioso central, etc.), sin necesidad de someterlas a procesos especiales de "reprogramación".

\section{EXPERIENCIAS REALIZADAS Y RESULTADOS OBTENIDOS}

\section{EN CÉLULAS TRONCALES EMBRIONARIAS}

El dato más llamativo ha sido el anuncio hecho por la empresa de investigación genética de EE. UU. "Advanced Cell Technology" (noviembre de 2001) de que por primera vez había clonado con éxito un embrión humano y que esa clonación no tenía por objetivo la duplicación de un ser humano (clonación reproductiva) sino el extraer del embrión clonado células troncales (capaces de convertirse en cualquier tejido del organismo) para su empleo en el tratamiento individualizado de enfermedades, como la diabetes juvenil o el Parkinson, sin producir rechazo en el paciente ya que se trataría de un autotrasplante. Las reacciones ante este anuncio han sido de diversa índole: rechazo al "cien por cien" del presidente Bush y de muchas personas y grupos; satisfacción y esperanza por parte de otros muchos (científicos, grupos de enfermos, personas de la calle).

La citada empresa, en colaboración con la universidad de Harvard y la Clínica Mayo, ha conseguido órganos similares a riñones y tejidos cardíacos bien organizados partiendo de embriones clónicos de una vaca; la implantación de esos órganos y tejidos en la misma vaca de donde proceden no induce rechazo inmunológico ${ }^{8}$. 
Cercanos a la aplicación humana se encuentran los resultados conseguidos con ratones, en los que se ha logrado reparar (en un 68\%) el tejido cardíaco infartado (inducido previamente dicho infarto) mediante la inyección directa al corazón de células troncales tomadas de la médula ósea del mismo ratón. Esto lo realizaron científicos del "Medical College" de Nueva York y del Proyecto Genoma del consorcio público (marzo de 2001). Anunciaron que preveían iniciar, a los tres años, los ensayos clínicos con pacientes humanos.

La Universidad de Standford ha anunciado (diciembre de 2002) que proyecta clonar embriones humanos para producir células troncales destinadas a la investigación médica. Es la primera Universidad de Estados Unidos que se introduce en este campo de investigación científica. Las investigaciones estarán a cargo de un Instituto, creado con una donación anónima de 12 millones de dólares, y se orientarán de modo especial hacia la búsqueda de una cura del cáncer. Por otra parte, se ha informado que las células troncales serán compartidas con otros científicos ${ }^{9}$.

El investigador español Bernat Soria, director del Instituto de Biotecnología de la Universidad de Elche (Alicante, España), afirma haber superado la fase de experimentación con ratones, a los que cura la diabetes (inducida) mediante la inyección de células troncales. Este científico se ha prodigado mucho ante la opinión pública a fin de lanzar una campaña a favor de la experimentación con embriones humanos sobrantes de la reproducción humana asistida.

Los primeros proyectos con células embrionarias aprobados en el Reino Unido (6/III/2002) no clonan embriones sino que trabajan con células de embriones sobrantes; sus objetivos son: la enfermedad de Parkinson y el tratamiento de la infertilidad.

El científico británico Ian Wilmut ha anunciado (octubre de 2002) que tiene previsto clonar embriones humanos dentro de seis meses. $\mathrm{Su}$ investigación se centra en utilizar la técnica de la transferencia nuclear para cultivar, entre otras posibilidades, células cardíacas que puedan ser 
trasplantadas al paciente para reparar un corazón que falla ${ }^{10}$. En una ulterior información, ha declarado que ya ha tramitado el permiso correspondiente a la Autoridad británica de Embriología y Fecundación Humana, pero concretando que la licencia solicitada es para utilizar un procedimiento de clonación conocido como partenogénesis, que consiste en activar un óvulo para que empiece a desarrollarse pero sin fecundarlo con un espermatozoide; el resultado sería un embrión genéticamente idéntico a la mujer que donó el óvulo ${ }^{11}$. Se trata de una técnica ya probada por la empresa estadounidense Advanced Cell Technology.

\section{EN CÉLULAS TRONCALES ADULTAS}

Los científicos del Instituto Roslin de Edimburgo -los creadores de la oveja Dolly- han conseguido transformar células adultas de vaca en células troncales sin necesidad de crear un embrión (febrero de 2001).

Un equipo de científicos de la universidad de Oslo y de una companía de biotecnología de Connecticut ha podido modificar células de piel humana de un individuo para que se comporten como células del sistema inmunológico de la misma persona, sin tener que pasar por la producción de embriones ni, consiguientemente, utilizar células troncales embrionarias. Los investigadores noruego-estadounidenses parten de la hipótesis de que todas las células de un individuo tienen la misma carga genética, aunque los genes se activan según el destino de la célula en el organismo ${ }^{12}$.

La existencia de células pluripotentes en el cerebro se descubrió hace muy pocos años. La tecnología necesaria para desarrollar las potenciales aplicaciones de esas células troncales no ha despegado todavía; hay experiencias de cultivo, mediante la utilización de diversos factores de crecimiento hasta conseguir formar neuronas y células específicas. En ello trabajan, entre otros, Constantito Sotelo, director del Laboratorio de Neuromorfología del Hôpital de la Salpétrière en París, y Derek van der Kooy, de la Universidad de Toronto ${ }^{13}$. Jonas Frisén, en su laboratorio de Estocolmo, ha logrado identificar células troncales en las pa- 
redes del sistema ventricular del cerebro adulto; sus investigaciones posteriores demostraron que esas células troncales adultas no sólo generan neuronas sino también otros tipos de células; cuando Frisén las inyectó en embriones de ratón descubrió que podían originar células de corazón, hígado, músculo, intestino y otros tejidos ${ }^{14}$.

En relación con las posibilidades de las células troncales adultas tienen un interés especial los experimentos realizados por Catherine Verfaille, directora del Instituto de Células Troncales de la Universidad de Minnesota (Estado unidos) ${ }^{15}$. Sus trabajos se centran en células troncales adultas que se encuentran en la médula ósea. Por el momento ha logrado convertir esas células multipotenciales en las características de los músculos, cartílagos, huesos, hígados y varios tipos de enronas. Tiene previstos proyectos de investigación para inducir la diferenciación de células troncales adultas en tejidos productores de insulina. La investigadora francesa es una abierta defensora de la investigación con células troncales adultas y de su uso terapéutico. Y ello como alternativa a la clonación terapéutica mediante el uso de embriones, cuyos reparos éticos son para ella evidentes.

\section{EN CÉLULAS DE OTRAS PROCEDENCIAS}

La Universidad Wake Forest y la empresa Adcance Cell Technology han logrado (en Estados Unidos), en experimentos con primates, la primera línea de células troncales obtenida de embriones creados artificialmente a partir de óvulos sin fecundar; consiguieron diferenciar esas células en neuronas productoras de dopamina (destruidas en la enfermedad de Parkinson) y en células específicas del músculo cardíaco. Para conseguir este avance científico, el equipo investigador trató 28 ovocitos de macacos con compuestos químicos e indujo en ellos una división semejante a la que sucede cuando pasan por la fase normal de embrión. Hay que tener en cuenta que, si se obtuviera este resultado con ovocitos humanos, la técnica únicamente tendría aplicación para pacientes de sexo femenino ${ }^{16}$. 
El científico español Juan Carlos Izpisúa y su equipo, en el Instituto Salk de La Jolla (California), han descubierto el mecanismo genético que dispara la formación de los órganos y de las extremidades en los vertebrados, incluido el ser humano. El control técnico de ese mecanismo ayudará a regenerar órganos dañados y miembros amputados ${ }^{17}$.

Científicos de la Universidad de Düsseldorf han conseguido trasplantar al corazón infartado de varios pacientes células troncales de su propia médula ósea, con resultado satisfactorio ${ }^{18}$. Varios grupos de científicos estadounidenses han presentado en Chicago (noviembre de 2002) nuevas técnicas experimentales para obtener células cardíacas a partir de células de sangre y de músculo del propio paciente; los investigadores ofrecieron evidencias preliminares de que las células cardíacas, una vez reintroducidas en el cuerpo del paciente, anidaron y proliferaron en las zonas dañadas del corazón, pero sin poder garantizar que ayudaran al corazón enfermo a contraerse con mayor vigor ${ }^{19}$.

El doctor Alfonso Castro, jefe de Cardiología del Hospital Universitario Juan Canalejo (A Coruña) afirma que regenerar el miocardio implantando células madre en la zona infartada supone "un vuelco completo para la cardiología y echa por tierra lo que hasta ahora era un dogma: las células del corazón no se regeneraban"20. En España, dos grupos trabajan en dos líneas diferentes. Uno de ellos emplea células extraídas del músculo del propio paciente para inyectarlas en la cicatriz causada por el infarto en el músculo cardíaco. Trabajan en ello los hospitales Universitarios de Navarra (Pamplona), Juan Canalejo (A Coruña), Valdecilla (Cantabria), Clínico de Salamanca y Gregorio Marañón (Madrid). De hecho, la Clínica Universitaria de Navarra ha realizado el primer implante, en España, de células troncales para regenerar un corazón infartado; esas células fueron obtenidas del músculo de la pierna del propio paciente, quien fue dado de alta después de comprobar una "evolución muy satisfactoria"21.

El otro grupo, encabezado por el Clínico de Valladolid, utiliza células troncales de la médula ósea, que se implantan con una inyección 
intracoronaria cerca de la zona dañada. En este sentido, ha tenido resultado positivo el implante de células troncales de su propia médula ósea en el corazón infartado de un paciente de 66 años, en dicho Hospital Clínico de Valladolid ${ }^{22}$.

Con estos dos resultados, España se coloca en la vanguardia de uno de los campos de investigación más prometedores.

POSTURAS DE LA OPINIÓN PÚBLICA Y DE LA COMUNIDAd CIENTÍFICA

OPINIÓN PÚBLICA

El debate sobre el uso terapéutico de células troncales humanas ha alcanzado el ámbito de la opinión pública. Basta ponderar las grandes ventajas terapéuticas que puede aportar (curación del Parkinson, de la diabetes, del Alzheimer, etc.) para provocar una reacción mayoritaria a favor. Esto es lo que se advierte en una ponderación espontánea y poco matizada de la cuestión. Tanto es así que se constata la intervención de grupos o de asociaciones de enfermos para pedir la investigación sobre células troncales humanas. Es lo que ha hecho la Federación de Diabéticos Españoles, promoviendo una campaña a favor del uso de las células troncales embrionarias ante el Ministerio de Sanidad ${ }^{23}$ y llegando hasta el Defensor del Pueblo, quien ha admitido la petición apoyada por más de un millón de firmas ${ }^{24}$.

Los medios de comunicación social reflejan las dos posturas, ofreciendo su ámbito comunicativo para difundir opiniones contrapuestas ${ }^{25}$. Fuera de las publicaciones de una tendencia definida, los restantes medios de comunicación reflejan más bien una postura positiva ante la investigación y el uso terapéutico de células troncales humanas.

COMUNIDAD CIENTÍFICA

Ha tenido especial relieve el informe, de 65 páginas, emitido por la Academia Nacional de Ciencias de Estado Unidos, a favor del uso tera- 
péutico de las células troncales humanas ${ }^{26}$. Esta postura es frontalmente contraria a la sostenida por la Administración estadounidense.

La Fundación Europea de la Ciencia, el más influyente organismo consultivo científico independiente de Bruselas, recomienda abiertamente que los países europeos legalicen, financien, impulsen y regulen la clonación de embriones humanos y la obtención a partir de ellos de células troncales útiles para trasplantes (junio de 2001).

El Observatorio de Bioética y Derecho, un grupo de expertos independientes, con sede en el Parque Científico de Barcelona, apoyó la investigación con embriones con fines terapéuticos: embriones sobrantes donados para la investigación; embriones congelados que hayan sobrepasado el límite legal de la crioconservación ${ }^{27}$.

Son muchos los científicos de ámbito internacional que abogan por el uso terapéutico de células troncales humanas, como Ian Wilmut ${ }^{28}$, quien se ha propuesto (octubre de 2002) clonar embriones humanos con fines terapéuticos; piensa conseguirlo en seis meses ${ }^{29}$. En Estados Unidos, 80 premios Nobel han dirigido una carta al presidente Bush en defensa de las ayudas públicas a la investigación científica con células troncales de embriones humanos ${ }^{30}$.

En España, la Comisión Nacional de Reproducción Asistida ha reiterado, en su II Informe anual (recibido oficialmente el 26 de noviembre de 2001) la recomendación al Gobierno de que permita investigar con los cerca de 40.000 embriones que permanecen congelados como producto sobrante de procesos de fecundación in vitro.

En el II Congreso Mundial de Bioética celebrado en Gijón (finales de septiembre y comienzos de octubre de 2002) fue unánime el rechazo a la clonación reproductiva y mayoritaria la aceptación del uso terapéutico de células troncales humanas. La principal voz a favor del uso terapéutico de células troncales embrionarias fue la del premio Nobel de Medicina Jean Dausset. En la misma postura se situaron: M. Palacios, J. Egozcue, y otros muchos. 
Lo más normal es pedir que se prohiba la clonación humana reproductiva pero que se permita investigar con embriones humanos congelados, de forma que se avance hacia el uso terapéutico de células troncales $^{31}$. Así se han manifestado bastante científicos, individualmente y en grupo. Un grupo de ellos (entre los cuales se cuentan: J. C. Izpisúa, M. Barbacid, V. Fuster, P. Puigdomenech, M. Salas) han pedido al presidente Aznar que se permita el uso de células troncales embrionarias para la investigación ${ }^{32}$. Esta petición ha sido reiterada, en varias ocasiones: por M. Salas, presidenta del Instituto de España, por el investigador Bernat Soria, por el bioquímico S. Grisolía, por S. Moncada, y por otros destacados científicos españoles.

En octubre de 2002, treinta y cuatro vicerrectores de investigación de otras tantas universidades públicas españolas, reunidos en Santa Cruz de Tenerife, han dirigido una carta al ministro de Ciencia y Tecnología pidiendo la autorización a experimentar con células troncales embrionarias, "mediante la utilización de embriones congelados disponibles o de aquellos que se puedan generar para su uso en terapia celular" y ello "bajo estricto control por parte de los responsables públicos". Cinco centros privados (Universidad Europea de Madrid, San Pablo-CEU, Pontificia de Comillas, Navarra, Pontificia de Salamanca) no suscribieron la carta $^{33}$.

Naturalmente, hay también personas de alta cualificación que mantienen posturas en contra, como G. Herranz ${ }^{34}$, César Nombela ${ }^{35}$, etc.

\section{DECISIONES LEGALES Y ADMINISTRATIVAS}

Ha sido de gran trascendencia la decisión del Gobierno del Reino Unido de permitir el uso de embriones humanos para el cultivo de líneas celulares en orden al autotrasplante. Después de pedir el parecer a una Comisión de expertos (denominado Informe Donaldson) ${ }^{36}$, decidió llevar la ley al Parlamento ${ }^{37}$. Por 366 votos a favor y 174 en contra, la 
Cámara británica de los Comunes aprobó (19 de diciembre de 200) la clonación de embriones humanos con el objeto de obtener células troncales capaces de convertirse en tejidos del organismo. Dada la delicada naturaleza del asunto, el Gobierno laborista dejó el voto a la libertad de conciencia de los diputados.

En los Estados Unidos, la Administración Clinton dio unas Directrices en la línea de la orientación abierta en el Reino Unido ${ }^{38}$. La decisión del presidente G. W. Bush ha pasado por diversas fases (de oposición total, de duda, de nueva oposición más matizada). Al final, la resolución definitiva es un tanto compleja, por no decir ambigua ${ }^{39}$. No habrá fondos federales para la obtención de embriones humanos con finalidad terapéutica; pero sí para el cultivo de líneas de células troncales ya existentes. La financiación queda restringida, en principio, a la investigación de 64 líneas celulares ${ }^{40}$. Esta decisión ha sido interpretada, por parte de muchos, como un ejemplo de "doble moral" y como un signo de una postura ambigua ${ }^{41}$. Por otra parte, el Estado de California (septiembre 2002) ha sido el primero de los Estados Unidos que decide impulsar la investigación con células troncales obtenidas de embriones humanos, oponiéndose así a la postura del presidente Bush.

Canadá es, después del Reino Unido, el segundo país que permite la investigación con embriones (febrero 2002). Las células sólo podrán ser utilizadas cuando sean donadas. Por otra parte, se prohíbe crear o clonar embriones humanos con fines científicos.

La comisión de Bioética del Senado de Bélgica ha aprobado (junio de 2002) una proposición de ley que permite no sólo experimentar con embriones (de menos de 14 días) sino incluso crear embriones en orden a la clonación terapéutica. De este modo, Bélgica se convierte en el octavo país de la UE en permitir la investigación con embriones, tras el Reino Unido ${ }^{42}$. Luxemburgo, Holanda, Portugal, Suecia, Finlandia y Dinamarca permiten investigar con embriones, pero no aceptan la creación de embriones en orden a obtener células troncales embrionarias. Carecen de legislación al respecto Italia y Grecia. La investigación con 
embriones está prohibida en España e Irlanda. Se acepta, con limitaciones, en Francia y Alemania.

En Francia, la Asamblea Nacional (enero 2001) ha dado vía libre a la investigación con embriones congelados sobrantes de los tratamientos de fecundación in vitro.

El Parlamento alemán ha aprobado (abril de 2002) la posibilidad de importar células troncales extraídas de embriones humanos a fin de investigar con fines terapéuticos, con tal de que no existan otras alternativas y sólo en proyectos que hayan recibido el visto bueno de una comisión de ética. Conviene recordar que la ley alemana sobre reproducción asistida no permite que permanezcan embriones sobrantes.

En España, los partidos PSOE, CiU e IU apoyan el uso terapéutico de células troncales embrionarias, pero el PP se opone con el argumento de que existen prometedoras alternativas. El partido del Gobierno prioriza los estudios con células troncales adultas ${ }^{43}$. Por quinta vez en los últimos meses el Pleno del Congreso de los Diputados rechazó (con los votos del Partido Popular y de Coalición Canaria), una iniciativa parlamentaria para abrir las puertas a la investigación con células troncales embrionarias, procedentes sobre todo de embriones sobrantes (15 de octubre de 2002) ${ }^{44}$. Esto no obsta a que la ministra de Sanidad haya anunciado reformas legales para investigar con células troncales procedentes de embriones sobrantes, si no son viables ${ }^{45}$.

A pesar de la negativa por parte del Parlamento y del Gobierno españoles, se ha anunciado que la Junta de Andalucía impulsará la investigación con células troncales a través de un grupo con sede en Sevilla que coordinará el investigador Bernat Soria ${ }^{46}$. Para dar seguridad jurídica a los científicos, el PSOE de Andalucía presentará en el Parlamento andaluz una proposición de ley para regular la investigación: acatará la Ley (estatal) de Reproducción Asistida, pero hará la interpretación de que los embriones que llevan congelados más de cinco años son "no viables" y por lo tanto se puede investigar con ellos ${ }^{47}$. El secretario general del PSOE ha pedido a los presidentes autonómicos socialistas que impulsen iniciativas de esta índole ${ }^{48}$. 
En Italia el Comité Nacional de Bioética ha hecho público un informe (28/XII/200) en el que examina cinco fuentes para la obtención de células troncales: fetos abortados, embriones heterólogos, cordón umbilical, células adultas, transferencia de núcleo para producir células troncales autológicas. El documento se decanta a favor del último procedimiento, con tal de que no pase por la producción de un embrión humano; en concreto, propone, como procedimiento innovador y alternativo, el uso de ovocitos sin que pasen por la fase de embrión humano. Este procedimiento ha sido denominado "vía italiana" para la producción de células troncales ${ }^{49}$.

El Parlamento Europeo, por presiones del Consejo de la UE, ha dado marcha atrás en su decisión de financiar los ensayos con células troncales embrionarias. Ha aceptado (septiembre de 2002) una moratoria, hasta enero de 2004, en la puesta en marcha del VI Programa Marco de Investigación cuatrienal (2003-2006) dotado con 17.5000 millones de euros. Sin embargo, la moratoria no es absoluta, ya que hay dinero para investigar si las células han sido aisladas en algún laboratorio ${ }^{50}$.

Rusia ha adoptado (abril de 1002) una moratoria de cinco años para la clonación de embriones humanos con finalidad terapéutica. Los dirigentes religiosos (cristianos ortodoxos y musulmanes) son los que con mayor fuerza han protestado contra la clonación humana. El Senado de Australia ha dado luz verde (diciembre de 2002) a un texto legal que permite investigar con células troncales obtenidas de los embriones sobrantes congelados en las clínicas de reproducción asistida; se prevé que la ley culmine su tramitación a principios de $2003^{53}$.

\section{DISCERNIMIENTO ÉTICO}

Hay que comenzar subrayando que la valoración moral del uso terapéutico de células troncales humanas ha de ser distinta si se trata de células embrionarias o de células somáticas. La primera de las hipótesis 
-servirse de células humanas en fase embrionaria- supone utilizar embriones, acción que ha de ser valorada de acuerdo con el estatuto antropológico de la vida humana naciente. En la segunda hipótesis se utilizan células troncales somáticas.

Por el momento, no veo que este segundo tipo de actuación, por él misma y en cuanto tal, lesione la dignidad de la condición humana; los fines terapéuticos a conseguir pueden justificar suficientemente el uso de células troncales somáticas. Por lo tanto, los procedimientos para la obtención, la investigación y el uso terapéutico (implante autológico) de células troncales humanas que no pasan por la fase de embrión no presentan ninguna dificultad desde el punto de vista ético.

La cuestión está en la valoración moral del uso de células troncales humanas cuando éstas se obtienen de embriones. A esta hipótesis me refiero a continuación.

\section{POSTURAS A FAVOR}

Más arriba señalé las posturas de la opinión pública, de la comunidad científica y de las instancias sociales normativas que están a favor del uso de células troncales embrionarias. Todas ellas no ven ningún contravalor moral, al menos decisivo, para oponerse a tal procedimiento.

Las razones que se ofrecen para apoyar esta postura positiva ante el uso de células troncales embrionarias son de diversa índole:

Se subraya que el uso terapéutico de células troncales embrionarias no es una clonación reproductiva, frente a la cual estas posturas se muestra, por lo común, radicalmente contrarias.

Se postula que para estos y otros procedimientos similares en la biotecnología actual no hay que "sacralizar" la "naturaleza". Le corresponde al ser humano "intervenir", mediante la ciencia y la técnica, en su condición y en su devenir biológicos.

La razón que, con más énfasis y con mayor frecuencia, se invoca es la "razón utilitarista". Al ponderar las posibles ventajas del uso terapéu- 
tico de células troncales embrionarias (curación de enfermedades de tanta trascendencia como el Parkinson, el Alzheimer, la diabetes, etc.) la balanza se inclina, de forma aplastante, a favor de este procedimiento.

Hay quienes justifican éticamente el uso de células troncales embrionarias afirmando que el embrión así producido no tiene propiamente el estatuto antropológico de embrión humano. Concretamente, según ellos, el cigoto así producido no tiene el mismo estatuto de un cigoto en orden a la reproducción. La célula originada para la clonación reproductiva no es un cigoto humano en sentido pleno: 1) ni por sus orígenes; 2) ni por su finalidad; 3) ni por su constitución. No existe auténtica "fertilización", en cuanto que no participó activamente el espermatizoide; de ahí que no tengan lugar las combinaciones y las mutaciones, que tanto contribuyen a la variabilidad de la especie humana. Lo que se da es una estimulación (externa) para que la célula se desarrolle hasta la fase de blastocisto, del que se obtienen células troncales a utilizar para obtener tejidos específicos para autotrasplante. Marcelo Palacios, de quien he tomado la argumentación precedente, propone que al cigoto producido para la clonación terapéutica no se le llame embrión sino nuclóvulo ${ }^{52}$.

Es preciso reconocer una gran debilidad en las argumentaciones éticas a favor del uso terapéutico de células troncales humanas embrionarias. La mayor parte de ellas no tienen en cuenta la realidad humana en sí, sino que se basan en la débil razón del utilitarismo. Por otra parte, la argumentación que niega estatuto de embrión al cigoto y al blastocisto producidos en orden al uso terapéutico no deja de ser, en cierto modo, una "pirueta intelectual", utilizando los datos objetivos con opciones pre-juzgadas.

\section{POSTURA ÉTICA CONTRARIA}

Son muchas las instancias jurídicas, éticas y religiosas que se oponen al uso terapéutico de células troncales embrionarias. Entre las religiosas, sobresale la postura de la Iglesia Católica, contraria a toda inter- 
vención que tenga como fin o como medio servirse de embriones humanos a los que considera con toda la dignidad debida a la condición humana.

El proceso científico-técnico del uso terapéutico de células troncales embrionarias tiene un evidente interés humano de carácter positivo, cual es el de curar enfermedades de mucha trascendencia para la realización de las personas, de las familias y de la sociedad. La ética en general y, más concretamente, la ética católica siempre ha tenido en gran consideración la "razón terapéutica" para justificar determinadas intervenciones sobre el organismo humano. Baste pensar en la aceptación ética de la terapia génica, tanto somática como también embrionaria. Sin embargo, la razón terapéutica no está por encima de la dignidad que le corresponde a la condición humana. Es precisamente esa dignidad humana la que no es asumida ni respetada en el uso terapéutico de las células troncales embrionarias.

A este contravalor primario hay que sumar otros que, por el momento, le acompañan. En primer lugar, para conseguir un resultado positivo se necesitarán muchas pruebas y los consiguientes "fracasos". Según los datos aportados por el equipo que clonó la oveja Dolly tuvieron que ser fecundados 177 óvulos para poder llegar al resultado deseado. ¿No se precisarán tantos o más para la clonación humana? ¿Es prudente y responsable iniciar un proceso en el que se prevé un número tan elevado de fracasos? En segundo lugar, la "desconsideración" ante la condición del embrión humano se extenderá cada vez más hasta alcanzar cotas imparables de insensibilidad frente a la peculiaridad de la condición biológica humana. ¿Dónde "se pone" el límite a las intervenciones si no se acepta el que "está puesto" por la misma realidad humana iniciada en la fusión de los gametos? Además, hay que tener en cuenta las posibles "instrumentalizaciones" a que puede dar lugar la aceptación jurídica de la clonación humana terapéutica. Es obvio el interés económico, con la consiguiente tendencia a disminuir la consideración ética ${ }^{53}$. 


\section{DOCTRINA DE LA IGLESIA CATÓLICA Y REFLEXIÓN TEOLÓGICA}

La Iglesia católica acepta el uso terapéutico de las células troncales con tal de que no sean embrionarias. Frente al uso de estas últimas -células troncales embrionarias- sostiene una postura frontalmente contraria. La razón está en la consideración del embrión humano con toda la dignidad que le corresponde a la vida humana.

Los argumentos para el rechazo del uso terapéutico de células troncales embrionarias así como para la aceptación de ese uso terapéutico en células troncales no embrionarias se encuentran ampliamente desarrollados en una Declaración (2000) y en un Documento (2001) de la Academia Pontificia para la Vida ${ }^{54}$.

Como reacción al anuncio (26 de noviembre de 2001) de que la empresa norteamericana Advanced Cell Technology había producido varios embriones humanos hasta el estadio de dos, cuatro, seis células, la Sala de Prensa de la Santa Sede ofreció un comunicado para expresar la postura católica contraria a tales experimentos ${ }^{55}$. Reproduzco la casi totalidad de dicho comunicado:

" (...). Los autores [del experimento] han confirmado que su intención no es la de dar origen a un individuo humano. Pero lo que ellos llaman en su artículo, como científicos, early embryo, embrión en el estadio inicial, ¿qué es? Henos aquí de nuevo con toda su actualidad ante el interrogante bioético, nunca acallado por la verdad, sobre cuándo considerar el inicio de la vida humana. En efecto, más allá del acontecimiento científico, sigue siendo éste el objeto de debate, estando fuera de duda -por indicación misma de los investigadores- de que nos encontramos frente a embriones humanos y no frente a células, como algunos quisieran hacernos creer.

Por consiguiente, el acontecimiento nos obliga reafirmar con fuerza que el inicio de la vida humana no puede ser fijado por acuerdo en un cierto estadio del desarrollo del embrión; el inicio de la vida se sitúa, en realidad, ya en el primer instante de existencia del embrión mismo. Esto se entiende fácilmente en la modalidad 'humana' de la fecundación 
entre ovocito y espermatozoide, pero debemos aprender a reconocerlo también frente a una modalidad "inhumana;, como es la reprogramación de un núcleo somático en una célula huevo: también con esta modalidad se puede dar origen a una nueva vida -como desgraciadamente ha demostrado el experimento anunciado- vida que conserva de todos modos su dignidad como la de toda vida humana a la que se le dé la existencia.

Por esta razón, a pesar de las declaradas intenciones "humanísticas" de quienes preanuncian curaciones clamorosas por este camino, que pasa a través de la industria de la clonación, es necesaria una valoración sosegada pero firme, que muestre la gravedad moral de este proyecto y motive su condena inequívoca (...).

Por otra parte, las investigaciones sobre las células estaminales indican que se puede recurrir a otras vías, lícitas moralmente y válidas desde el punto de vista científico, tales como la utilización de células estaminales tomadas, por ejemplo, del individuo adulto (existen diversas en cada uno de nosotros), de la sangre materna y de los fetos abortados espontáneamente. Este es el camino que todo científico honesto debe proseguir a fin de reservar el máximo respeto al hombre, es decir, a sí mismo".

Juan Pablo II ha recordado, con claridad, esta misma doctrina en su alocución al XVIII Congreso Internacional sobre Trasplantes (29 de agosto de 2000).

Ante el anuncio de que las autoridades autonómicas andaluzas tenían la intención de autorizar la experimentación con células troncales embrionarias obtenidas de embriones congelados o bien generados para tal fin, los obispos de Andalucía han hecho publica una Nota, en la que recuerdan la doctrina oficial católica de que "los embriones son seres humanos vivos en constante desarrollo y poseedores desde su concepción de una identidad genética propia y permanente. Por tanto, tienen derecho a ser respetados, independientemente de su etapa de desarrollo, y a no ser usados como material biológico de investigación, ya que su creci- 
miento es coordinado, continuo y gradual". También indican que existe una alternativa mejor en el uso de células troncales somáticas: "existen en los tejidos humanos células madres con la misma capacidad que las embrionarias y más fáciles y seguras de manipular, pues no tienden a diferenciarse espontánea e incontroladamente como las embrionarias, que pueden incluso dar lugar a tumores focales constituido por células heterogéneas (teratomas). Además, el avance de esta otra línea de investigación evitaría la aberración que supone destruir vidas humanas en desarrollo argumentando finalidades científicas o terapéuticas" $" 56$.

Con un horizonte más general, el Secretariado de la Subcomisión Episcopal para la Familia y la Defensa de la Vida (Comisión de Apostolado Seglar) ha publicado una Nota (19 de diciembre de 2002) ${ }^{57}$ en la que reafirma que "a la luz de los conocimientos biológicos actuales, el embrión humano es, a partir de la fusión de los gametos, un individuo humano con una identidad bien definida por un código genético propio y exclusivo, el cual comienza desde ese momento su propio desarrollo coordinado, continuo y gradual, de tal modo que en ningún momento puede ser considerado como una simple masa de células"58. De donde se deduce que "por muy notable que sea el fin perseguido, es inaceptable moralmente la producción, manipulación y destrucción de embriones humanos"59. No se deja de constatar que "hay otras alternativas moralmente lícitas, como la utilización de células madre procedentes de organismos adultos para lograr los mismos fines que se pretenden alcanzar con las células madre embrionarias. Ésta es la vía más razonable y humana que se ha de seguir para un verdadero progreso en este nuevo campo que se abre a la investigación y que ofrece una gran esperanza para muchas personas enfermas"60.

La reflexión teológico-moral se sitúa en la orientación marcada por el Magisterio eclesiástico y trata de articular un discurso justificativo y coherente de dicha postura: a veces, repitiendo la doctrina magisterial ${ }^{61}$; otras veces, buscando la conexión con los datos científicos ${ }^{62}$; algunas veces, insinuando matices complementarios ${ }^{63}$. 
CONCLUSIÓN

El debate ético sobre el uso terapéutico de células troncales embrionarias no debiera cerrarse con dos posturas enfrentadas entre sí. Creo que es preciso avanzar conjuntamente hacia dos objetivos de interés común: uno de carácter ético-jurídico y otro de carácter científico.

La ciencia ha de hacer todo lo posible por conseguir los resultados esperados de la terapia celular no mediante células en fase embrionaria sino mediante células somáticas que sean reprogramadas hasta retornar al estado de "totiponcialidad" o mediante otros procedimientos que no precisen pasar por la fase embrionaria. Ésta es la terapia celular que no atenta contra la dignidad de la condición humana y que, por otra parte, puede conseguir los resultados terapéuticos deseados.

El objetivo ético-jurídico se refiere a la necesidad de llegar a un consenso en el estatuto antropológico, ético y jurídico del embrión humano. Son muchas las voces que se alzan para pedir este consenso ${ }^{64}$.

Sigo confiando en que la razón humana -científica, ética, jurídica, política- sabrá encontrar los cauces adecuados para una comprensión cada vez más exacta de la condición humana y para la articulación de un proyecto cada vez más humanizador en el que se realice la felicidad de las personas y el bien de la sociedad en su conjunto. Es el criterio de la humanización lo que da sentido y orientación a las decisiones que se deben tomar en el campo del progreso científico-tecnológico. Por humanización se entiende, en expresión de la encíclica Populorum progressio, la realización "de todo el hombre y de todos los hombres", es decir, buscar el bien integral de todas las personas por igual" (n. 14). 
1 Sobre las células troncales humanas, ver: J.-R. LACADENA, Células troncales humanas: ciencia y ética: Moralia 24 (2001) 425-468.

2 J.-R. LACADENA, a. c., 434-435.

3 Ibid., 448.

4 Así lo ha hecho el Instituto Valenciano de Infertilidad. Información en: EL PAIS (16/XI/2001).

5 Información en: EL PAIS (24/IX/2002) 34.

6 Información en: EL PAIS (6/XI/2002).

7 De acuerdo con una información aparecida en EL MUNDO (31/XIL/2002) "más de 100.000 cordones umbilicales se encuentran almacenados en bancos criogénicos en todo el mundo, según los autores del estudio dirigido por el doctor Hal Broxmeyer, de la Fincultad de Medicina de la Universidad de Indiana, en Indianápolis"; este mismo estudio sugiere que "las células madre se pueden conservar más de tres o cinco años que hasta el presente eran considerados el lapso óptimo por los especialistas".

8 Información en: EL PAIS (3/VI/2002).

9 Información en: EL PAIS (11/XII/2002).

10 Información en: EL PAIS (14/X/2002); EL MUNDO (15/X/2002).

11 Información en: EL PAIS (26/XI/2002).

12 Información en: EL PAIS (5/v/2002) 33.

13 Información en: EL PAIS (30/V/2001) 33.

14 Información en: ABC (15/IV/2001).

15 Información en: ABC (28/V/2002). Entrevistas en: EL PAIS (28/V/2002) 30 y Domingos de $\mathrm{ABC}(1 / \mathrm{VI} / 2002) 6-7$.

16 Información en: ABC (1/II/2002).

17 Información en: EL PAIS (24/III/2001).

18 Información en: EL PAIS (25/VIIL/2001), (11/1X/2002).

19 Información en: EL PAIS (19/XI/2002).
$20 \mathrm{ABC}(18 / \mathrm{X} / 2002) 44$.

21 Información en: ABC (9/IL/2002), (17/II/2002).

22 Información en: EL PAIS (23/IX/2002), (24/IX/2002); ABC (22/IX/2002).

23 Información en: ABC (9//L2002).

24 Información en: ABC (18/X/2002) 44; EL MUNDO (18/X/2002) 33.

25 Así, por ejemplo: M. PALACIOS (a favor) - F. ABEL (en contra), La clonación con fines terapéuticos: Jano $59(2000)$ n. 1.348, 31; M. PALACIOS (a favor) - M. VIDAL (en contra), ¿Debe España permitir la clonación terapéutica?: EL MUNDO (20/IX/2000) 6-7; V. BELLVER (en contra) - J. MOSTERÍN (a favor), Las células madre y la clonación terapéutica: EL PAIS (3/X/2000) 15; C. LÓPEZ (a favor) - N. LÓPEZ (en contra), La clonación humana con fines terapéuticos: $\mathrm{EL}$ PAIS (2/XII/2001) 21. En contra: J. R.

LACADENA, Clonación humana terapéutica: ABC (8/IX/2000) 28. A favor: R. MATESANZ, El futuro de la clonación terapéutica: EL PAIS (6/X/2000) 12; M. PALACIOS, La clonación humana con fines terapéuticos. Algunos aspectos biológicos, éticos y legales: EL PAIS (16/IV/2000); B. SORIA - V. JUAN, Células madre, embriones, clonación: ¿el nacimiento de un nuevo paradigma?: EL PAIS (16/1/2002) 24; B. SORIA -P. PUIGDOMÈNECH, La investigación con células madre: EL PAIS (13/X/2002) 15; Ll. MONTOLIL - A. ARÁNEGA - A. RÍOS, Células madre: un debate necesario: EL PAIS (11/XI/2002) 16.

26 Información en: ABC (12/IX(2001) 52-53.

27 Información en: EL PAIS (18/XI1/2001) 28.

28 Información en: ABC (8/6/2002) 31 .

29 Información en: EL PAIS (14/X/2002).

30 Información en: EL PAIS (23/II/2001).

31 Así: A. RAYA - J. C. IZPISÚA, Investigación en células madre humanas: presente y ¿futuro?: 


\section{EL PAIS (26/XIV/2001) 28.}

32 Información en: EL. PAIS (14/XI/2001).

33 Información en: EL PAIS (26/XI/2002); ABC (26/X/2002).

34 Así: G. HERRANZ, Propaganda y realidad: Los Domingos de ABC (2/XII/2001) 11.

35 Diario EL PAIS (28/x/2002).

$36 \mathrm{Cf}$. C. CASALONE, Clonazione e cellule staminali - In margine al Rapporto Donaldson: Aggiornamenti Sociali 11 (2000) 716-730.

37 El texto tanto de las Recomendaciones de la Comisión de Expertos como de la Respuesta del Gobierno puede encontrarse en: Il Regno 45 (2000)471-476. También en Internet: www.doh.gov.uk.

38 El texto de las Directrices de la Administración Clinton ("Department of Health and Human Services - National Institutes of Health") puede encontrarse en: II Regno 45 (2000) 477479. También en Internet: www.nih.gov.

39 G. W. BUSH, Las células madre y la defensa de la vida: EL MUNDO (12/VIII/2001) 5.

40 Cf. C. CASALONE, Cellule staminali: la decisione del Presidente Bush: Aggiornamenti Sociali 9-10 (2001) 705-710.

41 Ver, por ejemplo, la amplia información ofrecida por el diario $\mathrm{ABC}(11 / \mathrm{VII} / 2001)$ portada, editorial, y pp. 30-31.

42 Información en: ABC (7/XIL/2002).

43 Información en: EL MUNDO (18/VII/2002) 34.

44 Información en: EL PAIS (16/X/2002).

45 Información en: EL PAIS $(24 / \mathrm{X} / 2002)$ y (6/XI/2002).

46 Información en: ABC (18/X/2002) 44; EL MUNDO (18/X/2002) 33.

47 Información en: EL PAIS (10/1/2003).

48 Información en: ABC (15/XI/2002).
49 CI. L. LORENZE'TTI, Lïpotesi italiana: 11 Regno 46 (2001) n. 873, 1-5.

50 Información sobre esta situación un poco ambigua en la UE: EL PAIS (29/VI/2002), (24/VIIL/2002), (5/IX/2002), (27/IX/2002), (1/X/2002), (2/X/2002); EL MUNDO (20/IX/2002)

51 Información en: ABC (7/XII/2002).

52 M. PALACIOS, La clonación humana con fines terapéuticos: Jano 59 (2000) n. 1.348, 31; ID., La clonación humana con fines terapéuticos. Algunos aspectos biológicos, éticos y legales: EL PAIS (16/IV/200).

53 Para un desarrollo más amplio de los argumentos contrarios al uso terapéutico de células troncales embrionarias, cf. J. R. LACADENA, Células troncales embrionarias humanas: fines y medios: J. J. FERRER - J. L. MARTÍNEZ (eds.), Bioética: un diálogo plural (Madrid, 2002) 117-152; C. NOMBELA, Células madre: un debate científico en su contexto ético $y$ social: $\mathrm{ABC}(22 / \mathrm{XI} / 2002)$.

54 Declaración de la ACADEMIA PONTIFICIA PARA LA VIDA, Producción y uso científico y terapéutico de las células estaminales embrionales: Ecclesia n. 3.013 (9 de septiembre de 2000) 35-38; Documento de la ACADEMINA PONTIFICA PARA LA VIDA. Células estaminales humanas autológicas $y$ transferencia de núcleo (Aspectos científicos y éticos): Ecclesia n. 3.045-46 (21 y 28 de abril de 2001) 46-50

55 'lexto en traducción castellana, que se cita, en: Ecclesia n. 3.078 (8 de diciembre de 2001).

56 Textos tomados de la Nota de los obispos de Andalucia sobre la utilización de embriones en la investigación sobre las "células madre": Ecclesia n. 3.128 (23 de noviembre de 2002) 9.

57 Texto en: Ecclesia n. 3.134-35 (4 y 11 de enero de 2003) 14-15. 
58 lbid., 15 (n. 4).

59 lbid., 15 (n. 5)

60 Mid., 15 (n. 5).

61 A. CHAPELLE, Le clonage d'êtres humains: Nouvelle Revue Théologique 123 (2001) 2745; J. R. FLECHA, Reflexiones éticas ante el fracaso de la clonación terapéutica: Ecclesia $\mathrm{n}$. 3.082-83 (5 y 12 de enero de 2002) 6-7; C. CASALONE, Clonazione terapeutica: distruggere per curare?: Aggiornamenti Sociali 53 (2002) 6-11.
62 A. BOMPIANI, Le cellule staminali e la clonazione terapeutica nel recente dibattito: Rivista di Teologia Morale 32 (2000) 543-563; M. P. FAGGIONI, Lavorare con cellule staminali: Studia Moralia 40 (2002) 85-114.

63 J. J. FERRER, La clonación de seres humanos: ciencia y conciencia: Sal Terrae 90 (2002) 587603; ID., El debate ético sobre la clonación humana: Razón y lée 245 (2002) 523-539.

64 Cf. R. JUNQUERA, El embrión humano: una realidad necesitada de protección: Revista de Derecho y Cenoma n. 12 (2000) 31-45. 